\title{
Sustainability Education Through Active-Learning in Large Lecture Settings: Evaluation of Four Out-Of- Class Exercises
}

\section{Jeff Baldwin, (PhD Geography)}

Sonoma State University, USA

doi: 10.19044/ejes.v3no4a57 URL:http://dx.doi.org/10.19044/ejes.v3no4a57

\begin{abstract}
Large classes on sustainable development present certain challenges. Often high student to instructor ratios encourage passive learning pedagogies. However, because sustainability education seeks to increase awareness and help students shift to more sustainable behaviors, more active learning is often prescribed by pedagogical experts. This study provides analysis of four out-of-classroom activities undertaken by students in recent offerings of an experimental course on sustainable development taught at Sonoma State University in California, USA. Those activities, innovated specifically for this course, attempt to increase learner centered activities in large classes that averaged 124 students. Analysis of open-ended reflections indicates that many students experienced raised awareness of sustainability issues. Beyond aspirational statements, student reflections and actual behavioral tracking indicate some shifts to lower carbon food choices in just four weeks.
\end{abstract}

Keywords: Food CO2e tracking, transportation CO2 tracking, campus as a living laboratory, learner-centered activity

\section{Introduction}

In this time of shrinking classroom resources, academicians are often encouraged to develop and employ innovative leaner-centered pedagogies which typically require more effort from faculty. The following research and analysis arises from attempts to increase active learning instituted in a large introductory course on sustainable development. That course was created in the summer of 2015 and mounted twice in the ensuing school year. One of my goals in designing the course was to create meaningful out-of-classroom activities that could be managed given the unavailability of instructional resources beyond my own efforts. My other goals beyond helping students understand and problemaitze more and less sustainable modes of 
development were to: 1) raise awareness of the students' personal relationships to climate change and unsustainable practices, and 2) foster changes in behavior, towards more sustainable personal and systemic practices.

This paper examines the efficacy of the four learner-centered activities I designed for the course. These include two $\mathrm{CO}_{2} \mathrm{e}$ (carbon dioxide equivalent) tracking worksheets, one focused on food and the second on transportation. These activities yielded specific quantitative data which reflect behaviors and any changes therein. A third activity took advantage of free public bus ridership for our students sponsored by Sonoma County Transit. The final activities exploit several campus as a living laboratory (CLL) efforts. For all four activities students submitted a 350 word reflection on their experience. I intentionally gave minimal instructions for the reflections to allow the students to identify the aspects of the experiences that were most meaningful to them.

Before describing the activities in greater detail the paper first revisits some of the relevant literature on sustainable education. In the subsequent section I briefly review coding methods and then provide a somewhat quantitative analysis of the spreadsheets and also the reflections. Analysis of the reflections provide insights into subjective experience not captured by the quantitative analysis, thus I draw from and share comments indicative of some common themes and experiences. I conclude with some suggestions to increase the efficacy first of the activities themselves and then of the empirical data as indicators of behavioral change.

\section{Sustainability Education: Consumers, Citizens, and/or Critical thinkers}

Sustainability education professionals offer a wide range of recommendations for course design. A primary concern is to help students understand their role in wider human-environment relations, and to motivate them to first take responsibility and to act in ways that they feel are more appropriate (Rachelson, 2014; Saylany and Blumstein, 2011; Chalkley et al., 2010). Isenhour (2015) argues that once instilled, changes in consumption ethics tend to continue and expand. Many argue that introducing students to life cycle analysis helps develop environmentally moral selves (e.g. Barnett, 2005). Along those lines, critical examination of Fair Trade products help people see their consumption as part of wider moral economies (Luerchford, 2008). Understanding the ways their consumption connects students with distant people and places cultivates affective perspectives (Feathrstone, 2011) which Moser (2007) argues is essential to shifts toward more sustainable consumptive behaviors.

Several authors offer critiques of framing people as consumers as the necessary focus of any paradigm shift. Leonard (2010) argues that while 
important, changing individual consumption behaviors is insufficient to achieve the wider goal of sustainability. Isenhour (2015) argues against what she calls "weak sustainable consumption", which aims to educate consumers about the problems caused by extraction, production, consumption, and disposal, and then counts on educated individuals working thorough markets to produce development that is sustainable. She states that there is considerable irony in expecting to solve problems arising from free markets and high consumption with even less regulation and additional consumption. Green consumption may in fact lead to increased commodity choice. Instead, she argues that state regulation is needed for "strong sustainable consumption". Alternately, Leonard (2010) argues that political activation of citizens may provide a way to create successful regulation of consumption.

The notion that we must provide our students with a deeper sort of understanding is supported by several sustainability educators. Wals and Blewitt (2010) argue that courses on sustainable development need to cultivate what they call gestaltswitching - the ability to alternate between explanatory world views and focus upon a variety of spaces in a global context. Robbins et al.'s Environment and Society: A Critical Introduction (2013) is a clear introduction to that project. The book very clearly introduces students to seven widely circulated discourses employed to diagnose human-environment dysfunction and their respective prescriptions for solutions to a range of cases. My students gained the ability to see environmental sustainability issues from each of these perspectives. Moseley et al.'s An Introduction to Human-Environment Geography: Local Dynamics and Global Processes (2013) provides a similar approach, but is not written so as to be accessible to most students in lower division general education courses in the California State University (CSU) system. Along similar lines, Sterling (2009) argues that courses on sustainable development should cultivate what he calls "ecological intelligence". Towards that end curriculum should aim to instill a critically holistic, inclusive, and systemic perspective; but one that also appreciates what already works well and encourages creative thinking about new alternative human-environment relations.

But what does this look like in a classroom? Working from Van den Bor (2000), Cotton and Winter (2010) offer several pedagogical techniques. Several of these are difficult to conduct and manage in a very large introductory class without teaching assistants, the usual case on CSU campuses. These include: role-plays and simulations, debates, problem based learning, and field work. The authors also recommend several learner centered activities which are possible in large and thinly supported classes: learning by doing rather than being told, designing group experiences, learning of one's role in human-environmental relations through experience, 
rather than focusing on memorizing course content. The authors suggest that activities work towards learner-centered curriculum which is said to more effectively links one's self to theory than does transmissive, lecture-centered learning. Learning by direct experience may also work to increase both awareness of students' roles in dysfunctional human-environment relations, as well as understandings of personal responsibility and agency to make changes.

The challenge then is to design and conduct a large, thinly supported, introductory general education course on sustainable development that both cultivates gestaltswitching (Wals and Blewitt, 2010) and meaningfully incorporates student-centered active learning. My focus here is on the latter. In the following sections I first describe the out-of-classroom activities I designed and incorporated into the class. I then present the outcomes of those activities, and discuss their efficacy and potential improvements.

\section{The Activities}

Over the two semesters course enrollment averaged 124 and classes were populated primarily by freshmen and sophomores. Students were asked to participate in four separate out-of-class activities. Two of these were initially inspired by a paper presented at the 2015 Conference of the Association of American Geographers by Alisa Hass. Those activities asked students to download an Excel spread sheet I designed which allowed them to daily track the carbon equivalent emissions produced separately by their transportation and by their food consumption.

Multiple sources for carbon dioxide equivalent $\left(\mathrm{CO}_{2} \mathrm{e}\right)$ emissions for both transportation and food are available, primarily among non-peer reviewed sources. My goal was not to create a tracking worksheet that would characterize all variability, but to provide the student with a reasonable estimation of their $\mathrm{CO}_{2} \mathrm{e}$ emissions. For the transportation tracker I had the students enter how many miles the travelled by automobile that day. I chose a mile per gallon coefficient of 20 and entered the $\mathrm{CO}_{2} \mathrm{e}$ in the spreadsheet calculation. Students had choices of driving singly, or riding with 2-4 other people in the car with accordantly lower $\mathrm{CO}_{2} \mathrm{e}$ emissions. The spreadsheet was designed to show grams of emission in the cell adjacent to their entry, In an effort to increase interest in and reward none motorized forms of transportation I designed the tracker to give carbon credits for minutes spent bicycle riding, skateboarding, or walking, specifically instead of driving, i.e. for trips that they would otherwise drive.

For food selection $\mathrm{CO}_{2} \mathrm{e}$ emissions I chose sources that encompassed $\mathrm{CO}_{2} \mathrm{e}$ emitted throughout the life cycle through extraction, production, storage, and distribution and consumption. The initial tracker offered students 106 different food and beverage choices. After feedback from the 
first class I added selections bringing the total to 121, increasing snack options and adding shrimp. Following the second class exercise, several students requested additional juices, and soy and almond milk and cheese specifically.

For both activities, students completed a one week training worksheet and submitted that through our University's on-line learning management system. I had students first complete and submit a one week training worksheet, and was able to very quickly identify problems with individual submissions and coach specific students in correcting errors. The students then sequentially tracked modes and quantities of transportation and food choices over two four week periods. At the end of the four weeks students submitted their worksheets and an unstructured 350 word reflection on their experience. I left these open ended as I wanted to see what the students felt was most important. Students who successfully completed the exercises received two points for their training week, seven points for the four week tracker, and three points for the reflection (of 100 possible points for the class). Thus the food and the transportation tracker each constituted twelve percent of their course grade. During the semester, my evaluation of submissions was cursory, verifying proper entry of data and meeting the word count target for reflections. Analysis was limited to calculating weekly class averages of carbon emissions. The worksheets are designed to make those calculations quickly in order to introduce aggregate results into class discussions.

Students engaged in two additional out-of-class activities. The first exploited a new program sponsored by Sonoma County Transit which allows students to ride busses without charge. The assignment was simply to make one bus trip. I provided only a link to the transit agency's website and a caution to plan their return trips. Students had five weeks to take their ride and then submitted an open-ended 350 word reflection on their experience (six percent of their grade). The first semester I had students include a selfie photograph to verify participation. That seemed unnecessary and so I eliminated that requirement the second semester. Again, because the Sonoma State University provides no teaching assistance beyond a few hours of undergraduate reader time, these reflections were not carefully evaluated during the semester. The value lies in the experience and the contemplation of that rather than in meeting pre-determined criteria.

Students also engaged in a campus as a living lab (CLL) experience. This activity articulates with a wider effort by CSU faculty and staff to create educational experiences through the use of our campus and its surrounding community and landscape. Students had the option to participate in one of three experiences: 
1) Sustainable buildings: a student led tour of our Recreation Center which was built to Silver LEED standards and features a wide range of sustainable practices (45 minutes).

2) Sustainable kitchens: a behind the scenes tour of our food service operations led by one of our professional managers focused upon increasing sustainable practices (45 minutes).

3) Environmental Technology Center agroecology gardens: hands on garden work led by a student expert (2 hours).

Through our learning management system students selected which of these three activities they would participate in. Students also enrolled in specific CLL activities which were scheduled at alternate times with enough advance notice so that all were able to successfully schedule attendance. Again, students submitted a 350 word open-ended reflection on their experience (six percent of course grade).

\section{Results and Analysis}

In an effort to draw meaning from the reflections I developed codes for each activity. This was a dialectical rather than a determinist process. To identify important themes I first read 15-20 reflections from each activity, and drew significant codes from what the students themselves wrote (Charmaz, 2014). I then performed an initial word search of specific key terms, highlighting appropriate instances using coded colors. I then read each reflection more thoroughly identifying any themes not identified in the first iteration of review.

\section{a) Bus ride}

For the bus activity I detected and coded for three self-identified subpopulations: first time riders, experienced riders, and all others. Here the two groups are aggregated as course conditions were similar as were results among the two groups. Portions are illustrated in Figure 1. I identified six common codes which are given along the horizontal axis of Figure 2. Each of the themes, or codes, required specific treatments of the texts. The selfidentification into sub-populations required a reading of each reflection, as did the codes for bus system dysfunction, and "will not ride again". The identification of "pleasant experience" was facilitated by word searches for the terms: good, relax, nice, friendly, enjoy. Unpleasant experiences were initially identified by key word searching for: confus, anxi, stress, creep, scar, nervous, safe, and afraid. It is important to note that this is not a survey. Students were not asked whether they would ride again, yet of all students forty eight percent volunteered that they would ride again, and fifty four percent of students who self-identified as first time ever riders volunteered that they would ride again. Additionally, sixty two percent of 
identified first time riders and fifty three percent of all riders reported that at least aspects of the bus trip were positive. Perhaps most significantly, of all students forty eight percent specifically stated, without prompt, that they would ride again; and first time riders most frequently reported positive experiences and an intent to ride again.

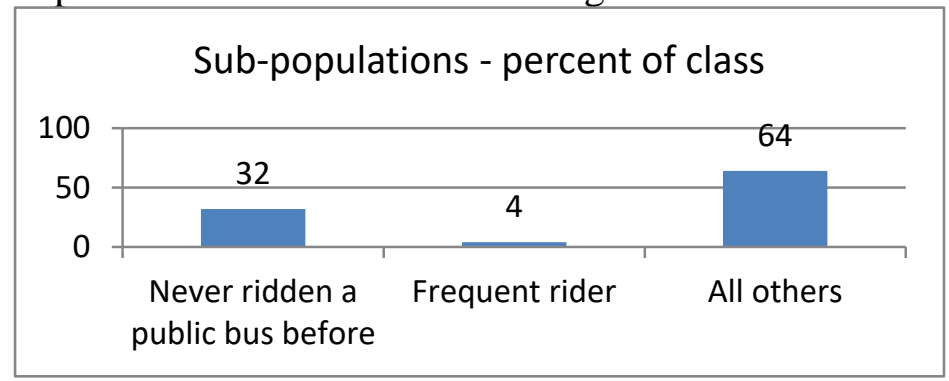

Figure 1. Percentage of students commenting on experience with public bus ridership.

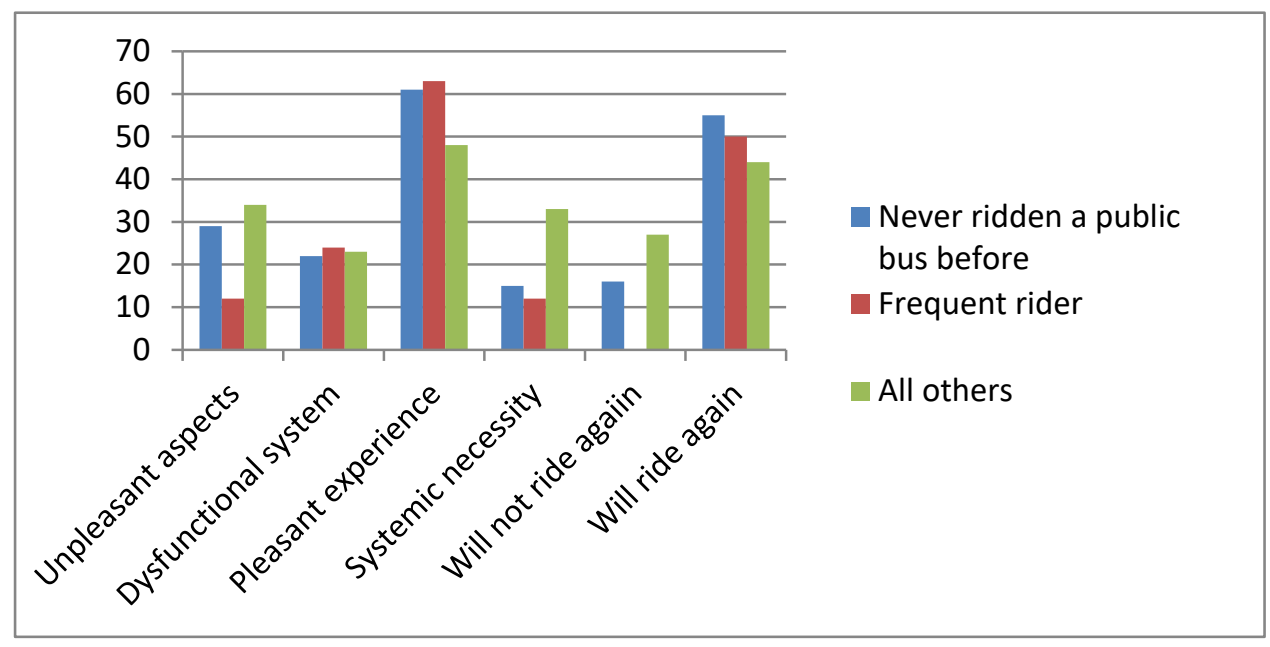

Figure 2. Frequency of common themes among the three sub-populations of ridership as percentage of total sub-population.

Alternatively, many students reported problems with the transit system. Of all students, thirty eight percent reported unpleasant experiences. Most of these involved either anxiety or fear about catching or missing a bus, and so were not about the system, but rather about their own inexperience. Some reported uninvited conversations with socially marginal community members, while others complained of odd smells. The second most common negative experience involved the inconvenience of the system due to late or infrequent bus service. Indeed, twenty two percent of all students commented upon the dysfunctionality of Sonoma County Transit. On the other hand, twenty six percent volunteered the idea that mass transit is a necessary part of a sustainable socio-environment. 


\section{b) Campus as a living lab}

The Recreation Center Approximately forty percent of all students chose either the Kitchens or the Recreation Center tours while the remaining twenty one percent chose the more active Gardens experience. Again allowing the reflections to inform the codes sought therein, for participants in the Recreation Center tour nearly ninety percent of all students commented specifically about the efforts to maximize energy and materials efficiency and re-use (see Figure 3). Comments about the use of natural lighting and carpeting that can be removed, recycled, and reinstalled were most common. That nearly one-quarter of the students used the specific phrase "never thought about" indicates success in raising awareness of energy and materials use efficiency. More notable is the number of students who made comments regarding intent to change behaviors. The difference in that category between the two classes is due in large part to the Recreation Center beginning an arrangement with TerraCycle which recycles batteries, bicycle tires, and foil lined energy bar wrappers, apparently a very commonly consumed food.

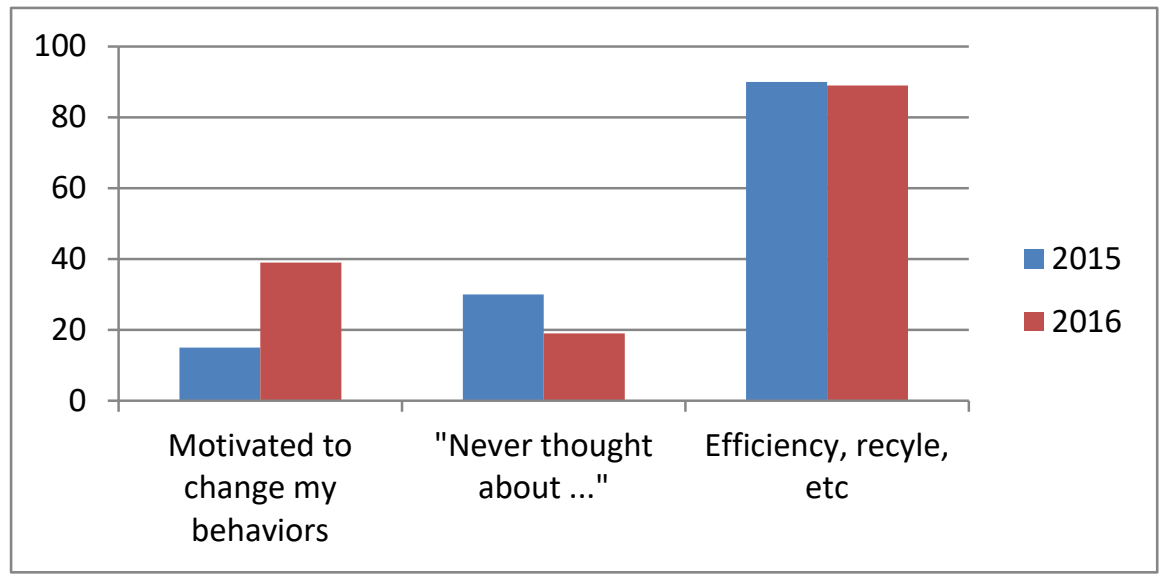

Figure 3. Indicators of awareness among Recreation Center tour participants (percent of total)

The Kitchens Responses to the food service tour also reflect differing emphasis in the presentations. Here the two cohorts' references to awareness of waste (seventy and fifty four percent) and discussion of composting (sixty three and seventy nine percent) is inverted. Over one-third of students commented upon the pride they internalized concordant with efforts at sustainability in the Kitchens. The other very common code focused upon a new awareness of the localness of the food at the kitchens. Among the eighty responses, "local" was used 106 times. Yet only twelve of the eighty students explicitly wrote that they should or would make an effort to buy more local foods themselves 


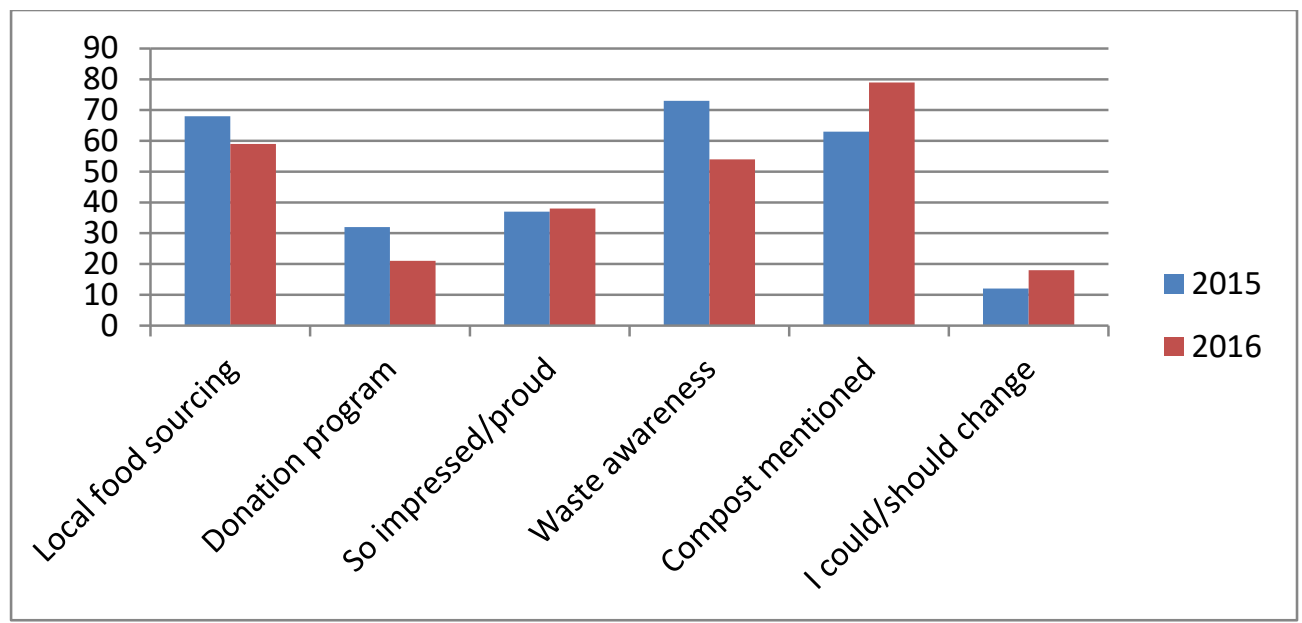

Figure 4. Most common themes among Kitchens tour participants (percent of total)

The Garden Of the three CLL activities, students who chose the garden experience reported much higher expectation of changed behavior. Indeed, forty six percent wrote that they intended to volunteer again. Self-selection probably played a part in that indicator of future behavior. I made clear that the Gardens would be a 2 hour commitment and that they would be actively working rather than more passively following a tour. Thus, students more interested in "doing" were more likely to select the Gardens experience. Consistent with that code, sixty two percent characterized the activity as a positive experience. None made negative comments beyond their expectations. Interestingly, thirty percent volunteered that they particularly enjoyed getting to work with and know new people and the community that formed around shared activities and common goals. Only two of the forty one participants indicated that they had worked at the gardens before.

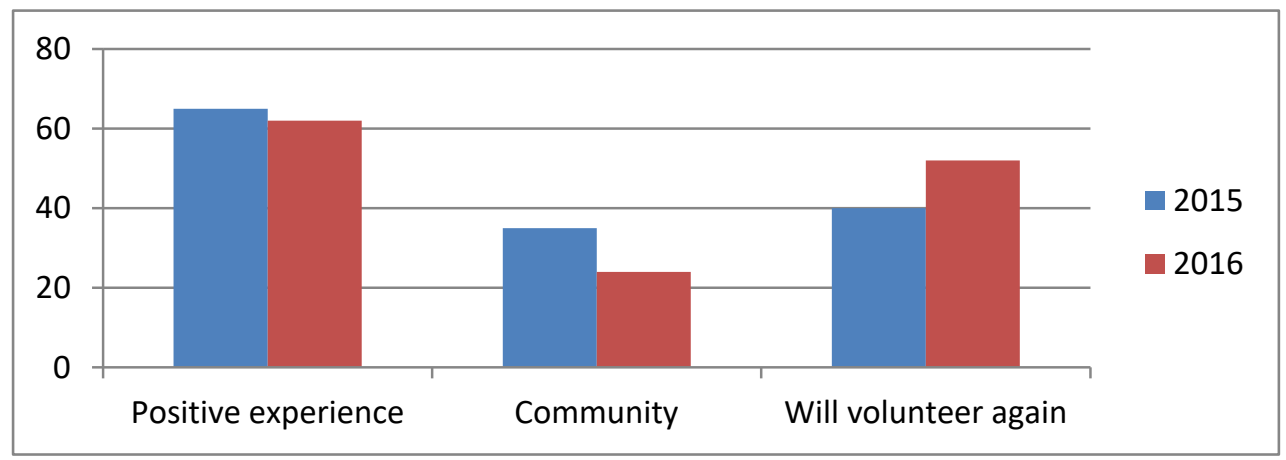

Figure 5. The three most common themes reported in reflections on working in the campus vegetable gardens (as percent of total participants). 


\section{c) Transportation $\mathrm{CO}_{2}$ e Tracker}

In the alternate semesters students engaged in the two tracking activities in different orders. In 2015, they completed the food tracker first. In 2016, I shifted that activity earlier in the semester in order to coincide with the bus ride activity. I timed all tracking activities so that they would not coincide with any holiday or break longer than three days.

As with the bus ride activity, coding revealed three mutually exclusive populations among the 201 respondents. In the most commonly reported theme, sixty seven total respondents (thirty three percent) suggested that they have, or more frequently will work to decrease their transportation $\mathrm{CO}_{2}$ emissions. Interestingly, among the group that simultaneously engaged in the bus ride and the transportation $\mathrm{CO}_{2} \mathrm{e}$ tracker, forty two percent pledged behavioral change. Among the 2015 class which performed the transportation $\mathrm{CO}_{2}$ tracker several weeks after the bus ride, only twenty six percent pledged a behavioral change. This suggests some synergy of affect in performing the two transportation related activities simultaneously. Consistent with that result, thirty two percent of the first group reported that they have not or would not change their behavior so as to decrease $\mathrm{CO}_{2}$ emissions. The exercise did produce one of the intended effects, thirty eight percent of all respondents indicated that their awareness of their $\mathrm{CO}_{2}$ emissions had been raised.

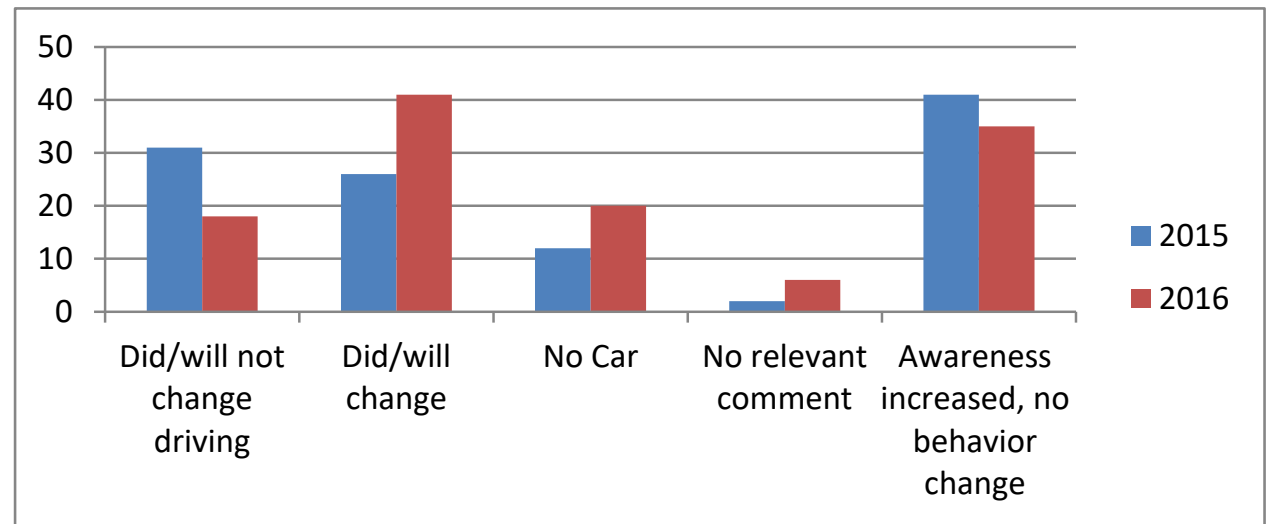

Figure 6. Percent of students reporting common themes regarding sustainable transportation

Among those who reported that they have not and do not intend to change their $\mathrm{CO}_{2}$ emissions several themes emerged (see Figure 7). Several reported that they are unable to decrease their transportation $\mathrm{CO}_{2}$ emissions because they must commute to school or work, and there are no viable public transportation alternatives. Others tried to either use public transportation or to form car pools, but did not succeed. Over one-fifth volunteered that a systemic change is needed in order to create a public transportation network that effectively moves people as they need in a timely fashion. Only sixteen 
percent of those that did /will affect a change also identified a need for systemic change. This suggests that those who aspire to change, but have not yet attempted to do so, may be less aware of the difficulty of making such a change than those who have tried. Finally, thirty six percent of these respondents volunteered that their awareness of the issue had been raised.

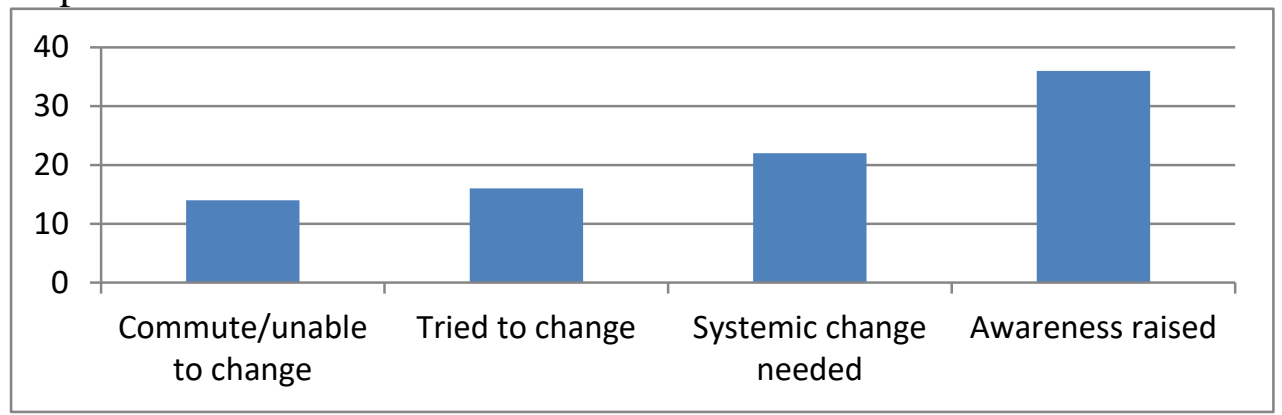

Figure 7. Most common themes among students who reported raised awareness but no behavioral change (percent of total).

In addition to submitting a reflection on their Transportation $\mathrm{CO}_{2}$ tracking experience, students also submitted the tracker itself, thus allowing for some analysis of actual behavioral change between the first and forth weeks. As Figure 8 indicates, average emissions were least in the first week, then increased approximately eighteen percent over the next two weeks, then declined, though not to Week One levels. In class discussions of his result students indicated that they travelled, primarily home, more on the subsequent weeks. Among a population that travels less than 100 miles per week on average, several students making weekend trips of several hundred miles could clearly increase average travel and emissions for the entire group.

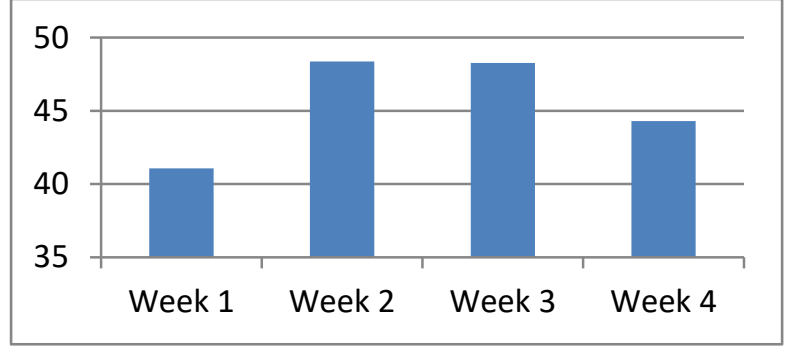

Figures 8. Average kilograms of transportation related $\mathrm{CO}_{2}$ emitted by each student over the four week study period. 
The trends illustrated in Figure 9 may also reflect non-routine travel to family homes. They certainly do not indicate general changes in behavior to decrease transportation $\mathrm{CO}_{2}$. Over the study period car sharing decreased significantly, from fifty nine to fifty percent of miles travelled (this figure incorporates the correction discussed below). This stands in contrast to the forty three percent of students who explicitly volunteered in their reflections that as a result of this activity they will increase their use of carpools and use alternative transportation.

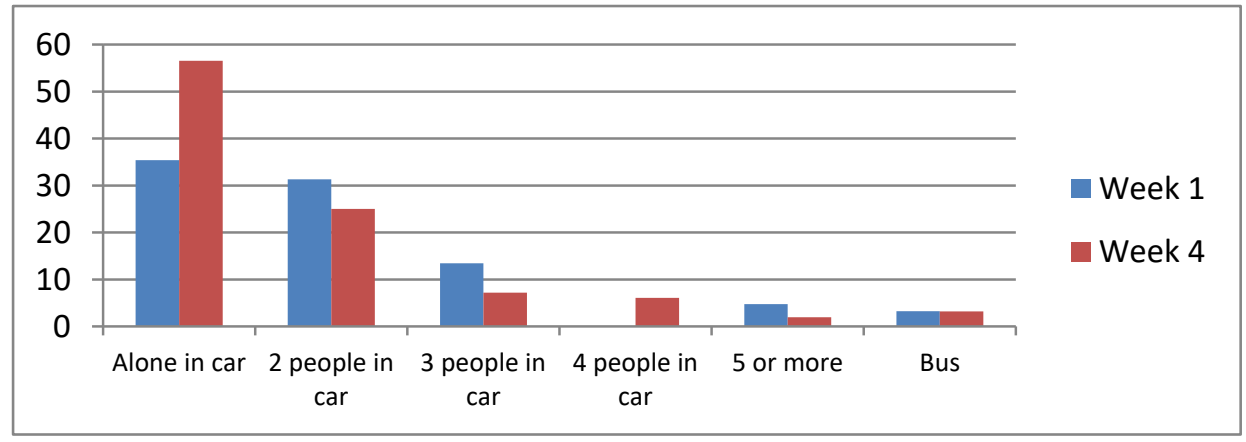

Figure 9. Combined two class use of motorized transportation modes (miles travelled) near beginning and end of study period.

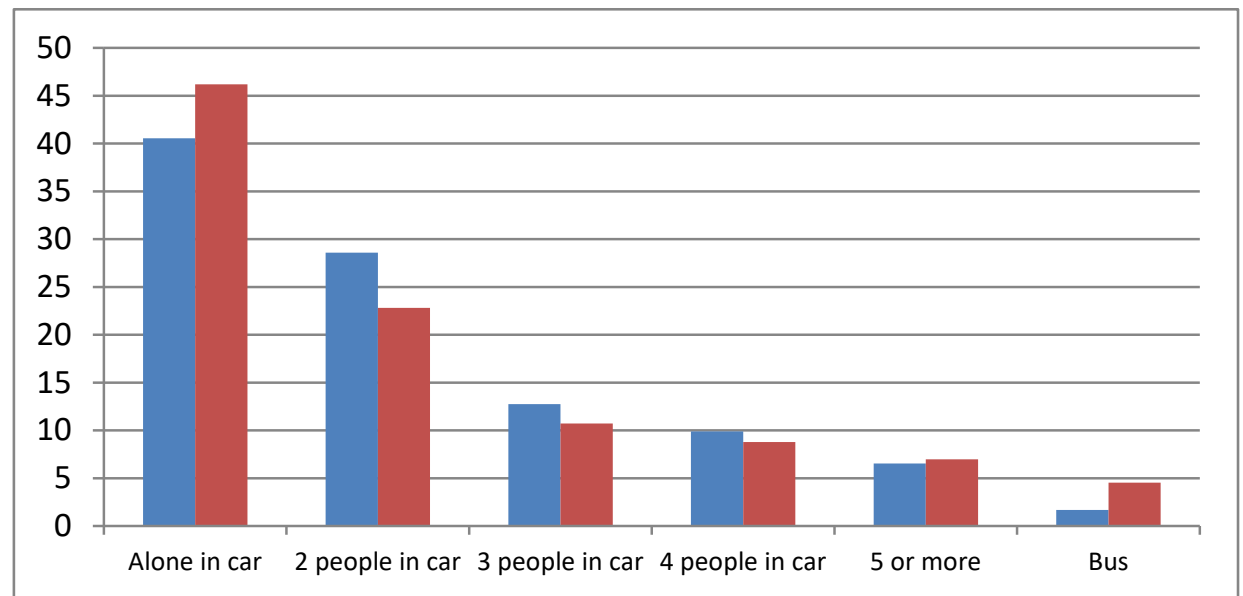

Figure $10 \mathrm{a}$ and $\mathrm{b}$. Illustration of the effect of a single bus trip home by one student in 2016 . 
Some critical review of outliers in student reports is in order. For example, Figure 10a indicates a significant shift in miles travelled by bus among the 2016 cohort. However, one student reported a single 1,530 mile bus trip. Figure 10b removes that trip and the trends look very different. With that correction the number of weekly student miles traveled alone in a car increased from forty one to forty six percent. Thus, even with a relatively large population of 98 students, here a single student was able to alter the frequency distribution for the entire cohort.

d) Food $\mathrm{CO}_{2} \boldsymbol{e}$ Tracker As with the bus ride activity, coding revealed distinct populations among the 205 respondents in the food related emissions exercise. One group claimed behavioral change while another stated clearly that they have not or will not change food choices in an effort to decrease food related $\mathrm{CO}_{2} \mathrm{e}$ emissions, while a third reported in increase in awareness but did not reflect upon their associated behavior. The clearest signal in the data is that far more students claim behavioral change (forty eight percent over both classes) than indicated no change (twenty one percent). The other notable difference lies between the two cohorts. It is important to note that readings specifically about environmentally degrading food production practices coincided with the end of the 2016 food $\mathrm{CO}_{2} \mathrm{e}$ tracker, but followed the 2015 study period by several weeks. Thus, curriculum related awareness may be partially responsible for the inter-cohort difference. Clearly the 2016 cohort has greater self-reported increase in awareness and claims of behavioral change. Accordingly, the 2015 cohort has a much higher incidence of self-reported intention to not change than the 2016 class (thirty two and six percent). Eight students focused so singularly on calories and personal health as to not comment on their diets' $\mathrm{CO}_{2} \mathrm{e}$.

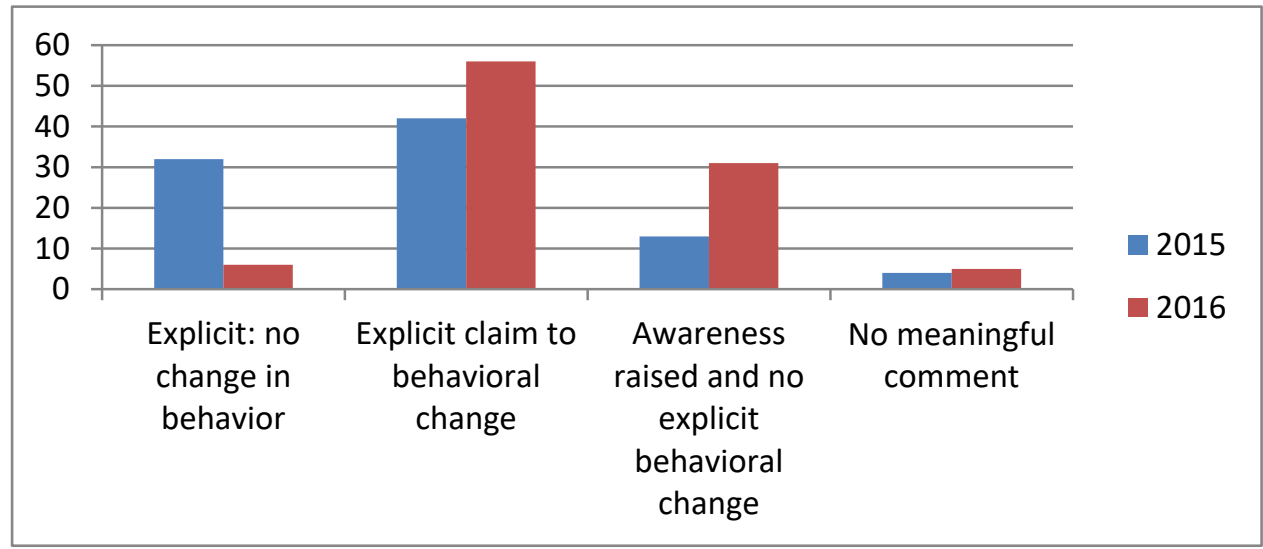

Figure 11. Percent of food $\mathrm{CO}_{2}$ e self-identifying response to the exercise. 
Analysis of the students' spreadsheets provides some evidence of behavioral change among low and high $\mathrm{CO}_{2} \mathrm{e}$ choices. Consumption of spinach salad with tofu, one of the lowest carbon entrées at 550 grams of $\mathrm{CO}_{2} \mathrm{e}$ per serving, increased from twelve servings in Week One to forty seven in Week Four. The three most popular entrees also reflected some carbon awareness. High carbon dishes were consumed less: pepperoni pizza slices with 640 gms $\mathrm{CO}_{2} \mathrm{e}$ decreased from 208 to 164 servings, and cheese burgers at 2830 gms $\mathrm{CO}_{2} \mathrm{e}$ decreased from 133 to 116 servings. At the same time, chicken with the lowest $\mathrm{CO}_{2} \mathrm{e}$ per serving for a 4 ounce serving of meat (760 gm CO $\mathrm{g}_{2} \mathrm{e}$ ) increased from 198 to 247 servings.

\section{Qualitative Analysis of Change in Awareness and Behavior}

The reflections submitted by each student for each of the four activities provide more qualitative evidence of their changing awareness and potential for behavioral changes. In the following discussion I seek to draw out dominant themes and specific comments indicative of change in awareness and behavior, and reasons for the lack of change. In all four cases students were instructed to "write a 350 word reflection on their experience". The prompt is intentionally open ended to allow the students to identify and describe what they found interesting and important, and yielded the type of responses I intended. Each of the four activities produced approximately 100 reflection constituting about 35,000 words of text in each of the two semesters, for a total of about 800 reflections and over 250,000 words. In addition to reading the reflections and highlighting themes, I again used key word searches to initially identify relevant comments.

a) Bus ridership The polarity in the quality of experience reported by students here is striking. While many reported an often surprisingly satisfying experience, many others commented upon systemic dysfunction:

there was barely anyone on the bus. This seemed like it could've been a little damaging to the environment because the bus was putting out a ton of carbon dioxide for only a really small amount of people..... I like being able to cut back on the amount that I drive just by myself, but it makes me wonder if using the bus in a smaller town is really worth it.

Comments specifically about timeliness and inconvenience were more common. Many students related having to wait for busses for over an hour and many of these recommended more frequent service and better adherence to schedules. Many of those students also referred to the convenience of using their own cars:

[This experience] also reminded me of why I love my car so much, but also to the reality of the matter: when I rode the bus I was not impacting the environment as greatly as I am today. It shows the 
common problem with people and the environment today, which is that we knowingly destroy it because it is the easier or cheaper thing to do.

Another wrote that:

Overall, my experience on the bus was kind of eye-opening, but I definitely prefer to drive my car. It feels slightly strange to be surrounded by a crowd of people that you do not know, and to have no control over the vehicle.

Many students echoed this dilemma, the awareness of riding the bus as better for our common good balanced again the discomfort and personal costs of being among strangers and of not having control.

As the quantitative analysis indicates, anxiety over lack of control and of sharing public space was a common theme. Many of those students also reported satisfaction with challenging and overcoming that discomfort; one student wrote "... this experience made me realize that public transportation is not as scary as it seems, and that I can incorporate more public transportation into my lifestyle." Perhaps even more significantly, a small number of students reported wider life lessons. Some of these came through encounters with permanent residents near campus: "Was it ideal? Not really. Yet, I did enjoy it. I even helped an older lady with her front yard work on my way. All in all, I truly enjoyed my bus ride experience." Others wrote about encounters with residents on the bus ride itself:

I did find the bus ride to be very informative. The reason being because I got to see many different people who lived many different lives on the bus ... a lady got on and sat across the way ... [W]e started talking to her about how she rides the bus everyday ... because she wants to become more environmentally sound .... it made me realize how much emissions and smog going into the atmosphere could be depleted by taking more and more cars off the road.

Several students related uncomfortable encounters with probably homeless residents; however, a few reported positive encounters and significant learning:

There was an older lady on the bus who started asking me about food at around 7am, it gave me the creeps at first but she meant no harm and was extremely friendly after getting to know her a little. I didn't want to know if this was her only form of transportation, she had many bags with her full of things. I had the feeling that she was probably homeless but she was extremely happy and content it felt like.... This experience was eye opening, ... It felt good as weird as it may sound to be on the same bus as the older homeless lady, I don't 
know how to phrase it I felt equal to her in some sense. It felt good to know that she was happy and not angry at the world.

This and similar experiences are lessons that are very difficult to replicate in a classroom of any size.

One of the most common themes among those who came away with a favorable view of the bus system was a change of opinion. Many students expressed surprise at the quality of the experience. One wrote "In the end, we realized bus rides are not as scary as we thought they were", and another: "I always thought that buses smelled bad, had sketchy people on it and took forever to get to where you wanted to go. Yet I was completely wrong." And finally, a comment that would encourage most college professors:

After this experience I'm amazed that I haven't utilized this resource the whole time I've been at Sonoma State or even back home. It concerns me that our society almost demonizes the transit system as I did before rather than glorifying this free and clean way of transportation. Thank you Dr. Baldwin for this eye opening assignment.

b) Campus as a living laboratory Again, students had a choice of three activities: Recreation Center, Kitchens, or Garden. Among the students who visited the Recreation Center one of the most frequently reported lessons learned regarded the invisibility of the sustainable technologies employed in green building design. Typical of this lesson, one student wrote:

This out of class activity took me by surprise a little bit because I came out of it with information I wasn't expecting. ... [the building] had the capabilities of utilizing new technologies to be more sustainable. Most of these technologies can go unnoticed.

And,

I absolutely loved this experience, as it really opened my eyes as to how environmentally sound the building actually is. After seeing this, it really makes me wonder why other places aren't doing this.

A majority of the students reported upon the various efforts at reusing and recycling featured in the tour: "all the furniture is made of recycled material. For example, the tables are made from $80 \%$ recycled glass or recycled money that is out of circulation." Several students also wrote about generalizing these technologies to other buildings, to making more systemic changes: "I am now curious to see how realistic it would be to have this form of heating in the home", and "I loved this lab because I know what I am doing to sustain the environment when I go to the gym and I find it amazing and inspiring how green friendly Sonoma State University is, and I love it." Several of these comments also indicate the value in using a building that many students associate with positive experiences, in this case 
with recreation, for such a tour. A building associated with classrooms might not have produced the same degree of affinity and pride.

Among students who participated in the Sustainable Kitchens activity, the two most common themes involved decreasing food waste and local sourcing. Regarding waste, many students commented upon specific efforts to reduce, repurpose, or recycle waste, most commonly the change from trays to plates:

One of the smartest changes they underwent in the switch was the idea behind changing the trays to plates. The idea was that people tend to eat more with their eyes, so having the trays students would fill the trays as much as they could. Now that there are plates students have less room to put food and they tend to not keep getting up to get more.

Many students were also intrigued with efforts by the kitchens to buy locally produced foods:

[The kitchens] pride themselves on purchasing only local produce from surrounding farms in Sebastopol, Petaluma, Napa, San Francisco etc. I was surprised to hear that the furthest that we import any of our produce is "maybe" Mexico or Arizona for things like watermelon that tend to go out of season in California.

Interestingly, while students were apparently impressed with efforts to source locally, and many students indicated their efforts to buy locally themselves in their food $\mathrm{CO}_{2} \mathrm{e}$ tracking exercise, none extended local purchasing to personal behavior in the Kitchens activity.

As with the Recreation Center activity, several students did report that they have subsequently engaged in educating others about what they learned at the kitchens. One student related sharing lessons learned with their family: "My parents loved to heard these neat facts about our schools composting and improvements made over the last few years here at Sonoma.” Again, Walsh et al. (2016) report that this sharing with family was central to and very common amid their study involving High School students.

Among the relatively small cohorts (forty one total) who elected to participate in the Gardens activity, many students commented upon the satisfaction they felt in their own agency:

I felt really good about the work we had all done to help the Environmental Technology Center Garden. I learned from this activity that if we make the work fun then we can finish before time and if we all work together and cooperate we can get a lot done in a small amount of time. 
Several reported that they already had or intended to begin their own gardens: "This activity was mostly insightful because I learned that it's something I really enjoy. Since then, I've been working with a friend on starting a garden." While many students characterized their experience as enjoyable, many went beyond that to comment upon its meaningfulness: "I love being in the garden surrounded by colors, dew drops, and life, feeling blissful as I transcend into the environment, so to the garden I return to revel in it some more ^ $\wedge$ " and another wrote "What I liked about the garden is that Jake said they produce enough food every year and they give it to homeless and the hungry to feed those in need of food." Perhaps predictably, the students who chose the more active learning exercise see themselves as being more active in pursuing lessons learned through their CLL activity. As Figure 12 illustrates, of the CLL activities, the garden experience elicited a greater commitment to behavioral change.

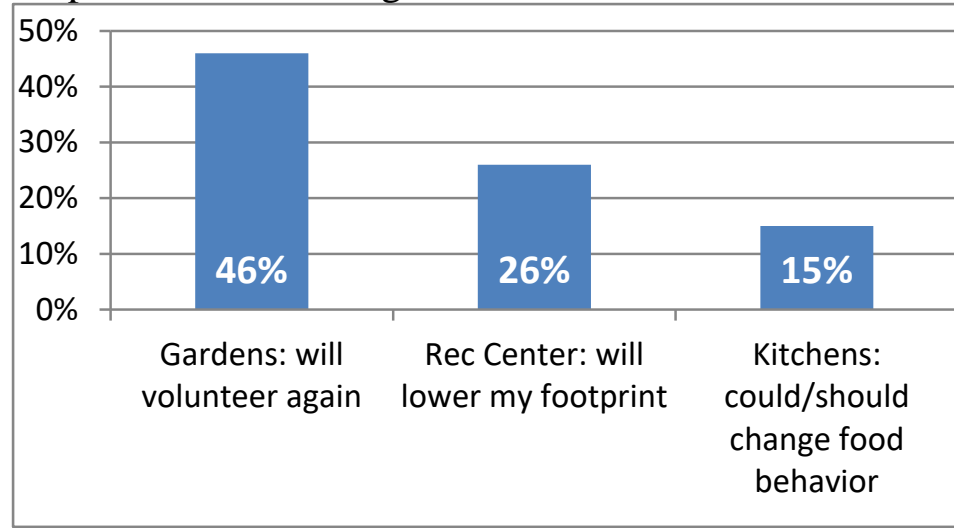

Figure 12. Percent of cohorts pledging resultant changes in behavior.

$\mathrm{CO}_{2} \mathrm{e}$ tracking and behavior: transportation Given the goals of this study are to raise awareness of personal relations with sustainable practices and to foster changes in behavior, the hope is that comments such as the following would be common:

a huge difference can be made in our net emissions by even walking for a couple minutes. I made it a point to walk. ... Something that helped me reduce the amount of carbon from driving was from attempting to carpool for errands and events as much as possible. My friends and I would plan on going to the grocery store together and visit the mall.

However, many of the student reports of changes in behavior regarding transportation related $\mathrm{CO}_{2}$ emission were primarily aspirational (e.g. I will, I plan to). While hopeful, these responses are also troubling. A national study by Lieserowitz et al. (2013) gives some indication of the relationship between aspiration and action regarding efforts to stem climate 
change. The authors found that survey respondents often do not act on their aspirations. My analysis of that study finds that of the respondents who stated that they would write to their representatives in the next year, 29 percent did not.

Accordingly, many students reported an increase in awareness, but did not report a change in behavior. One wrote that "Overall, this experience was eye opening and I realized that I need to stop driving as much as I am and try and carpool and walk more places than I do now." Along similar lines another wrote that "Tracking your everyday life via this worksheet helps people realize, as their $\mathrm{CO}_{2}$ numbers go up, that it probably isn't the best for our planet." Yet, in many such comments, no indication of behavioral change is evident.

Others reported realizing the excess of reliance upon personal cars: "For example, this past weekend my friends and I drove 3 separate cars to get food ... My friends were being princesses and did not want to ride in the back seat." Others reported driving around campus, a maximum of 1.3 kilometers, or to a nearby convenience store which is 700 meters from the furthest dorm. Others attempted to change behavior but were unable to maintain that change for even three weeks:

I soon realized during the second week that I was making these short unnecessary trips to the grocery store, every single day to pick up small items. ... During the third week I tried picking up all of the crap food that I would eat during the week in one single trip... The forth week I did not consider trying to reduce or thank about my mileage and just drove when and where I pleased.

Many students did report an increase in awareness. Typical of this theme, one student reported that "This assignment was a real eye-opener. From now on I will definitely make an effort to emit less $\mathrm{CO}_{2}$ by biking or walking instead of driving some places." Yet forty three comments along this theme make no mention of subsequent behavioral change.

Of 205 respondents, thirty indicated that they will or could ride their bikes more. However, eighty five respondents volunteered that they cannot ride because they are unable to, do not have access to a bike, or their travel distances are too far. Several wrote that they do not know how to ride. Another seven percent (fourteen individuals) indicated that they do ride bikes, but only 6 volunteered that they had added riding to their transportation modes during the exercise.

Interestingly, one area of reported behavioral change focused upon behavior with friends. There, many students reported successfully increasing carpooling and some of these wrote of changing their friends' awareness. One student reported that: 
It was fun encouraging my friends to count their miles and examine their $\mathrm{CO}_{2}$ admissions. I believe this assignment had an impact on my friends ... We learned if you want to get groceries and get a new shirt, go to Target and kill two birds with one stone.

Though fourteen students did report sharing their new awareness of transportation related greenhouse gas emissions with friends and family, this study differs from the Walsh et al. (2016) which found nearly ubiquitous sharing with friends and family. While sharing awareness of transportation related greenhouse gas emissions was not commonly reported, only eight students reported sharing their new Food $\mathrm{CO}_{2} \mathrm{e}$ awareness with family and friends.

\section{$\mathrm{CO}_{2}$ e tracking and behavior: food}

Climate change education is bedeviled by the invisibility of the effects of both one's own carbon emissions and the aggregate emissions of humanity. One of the goals of the food $\mathrm{CO}_{2} \mathrm{e}$ tracking exercise was to produce a more immediate understanding of the importance of one's own emissions beyond transportation. Though rare, a few students noted this failure to connect, even while in a class on sustainable development. One student reported that

I spoke to a classmate that was tracking down her food also, and she told me that she didn't feel guilty ... because she was not physically seeing any damages on her part of her carbon dioxide emissions. Along similar lines, another wrote:

Although, recording my results everyday; it ultimately didn't affect my choice of not eating a certain foods. I believe that this is because I can't see the effects in hand.

On a similar note several students reported a sense of futility, a lack of agency. One wrote "But what can I do? For I am just one person, would me changing my diet really make a change in the world? Sometimes I feel it's a lost cause for the atmosphere." Another expressed resignation: "let's be real here, no one is going to consume less because we are all selfish and enjoy the wonderful delights of food." Of our collective future, one student wrote: "Will they see the same beauty in nature as we do today, or will the catastrophic effects already have begun? I just don't know what to do anymore." While poignant, these sentiments were not in the majority.

Consistent with the plan of the class, more often students responded to feelings of futility with new understandings of personal agency. For example: "This tracking system ... makes you realize how you as a single person on earth can make a huge impact." Often students associated the personal agency gained through their new awareness of food carbon to a hopeful systemic scale: 
... from this assignment I gained not only awareness of my own carbon footprint, but applied it to a larger, national scale. If American's become educated and aware of what living a sustainably entails, it may be possible to significantly cut emissions.

Several others explicitly called for systemic cultural change:

positive shifts in consumption patterns on a large scale are more likely to work if institutional, systemic and cultural mechanisms are in place which make the right choice an easy one [for individuals] to make", and "The way we currently produce food needs a drastic change if we want to continue to live on Earth."

A number of students also reported satisfaction with the activity and what they were able to teach themselves. Comments included: "I am learning more about carbon emissions through this experiment than I would've any other way" and "I never realized until this activity that if I changed my diet I could make the world a little better and create a better atmosphere". As with the other activities, many students also commented on the wider meaning of the exercise: "I believe the significants from this assignment doesn't just come from selfawareness and change, but rather the effect of this class (I included) spreading awareness to others", and

If everyone did a carbon log for their food they would realize just how much carbon is emitted and then hopefully people would want to change eating habits. This tracker was the next best step that I could think of other than our earth dying in front of us.

This self-learning is among the central goals of these exercises. Several students wrote of insights gained into important course concepts through the activities:

I realized that I was perpetuating one of the problems I had studied: externalities. ... that simply because ... I had not documented my diet's carbon output, that carbon simply ceased to exist altogether.

Such experiences were hardly universal, but as the numerical analysis in the previous section indicates, both the food and the transportation $\mathrm{CO}_{2} \mathrm{e}$ trackers proved valuable modes of learning for most students

Economic exclusion does pose one concern here. Several students reported that their income kept them from being able to lower their food $\mathrm{CO}_{2} \mathrm{e}$ emissions. Several comments are represented by: "I'm thinking from $a$ poor college perspective here and when I buy food/meats, I buy the cheapest I can find. Free range and grass fed meats are just to expensive for me to buy". This statements and others like them suggest that some explicit address of lower cost modes of food $\mathrm{CO}_{2} \mathrm{e}$ reductions is in order. 


\section{Conclusion:}

Clearly, these student-centered activities increased student awareness of sustainable practices and of the ramifications of their daily acts. The question that troubles any conclusions asks of actual changes in behavior. Many students did change their food choices away from higher to lower CO2e entrees. Also, combining similarly themed activities such as the public transit experience with the transportation carbon tracker does seem to offer learning synergies. A fifteen week class may not allow enough time for students to make changes in transportation choices, nor a sufficient period to evaluate any changes. In an effort to address this issue I plan to introduce the transportation and food $\mathrm{CO}_{2} \mathrm{e}$ tracking to an upper division class so that they will track emissions for two weeks at the beginning of the fifteen week course and for two weeks at the end of the course. This will allow ten weeks for students to affect changes should they chose.

In student evaluations of the course, comments about the learnercentered activities were overwhelmingly positive. Students enjoyed the opportunity to learn on their own outside of the classroom. They also liked the decreased weight on exams in lieu of these activities. As an instructor, managing the submissions was not onerous, taking as little as five hours to download each activity's submissions, record their completion, and notify students of irregularities (mostly file format changes moving from PC to OS operating systems).

Furthermore, this study helps to identify areas of weakness in campus sustainability efforts and suggests ways to address those. Students commented on a paucity information regarding the carbon footprint of foods as well as low carbon foods available at our central food services venue. The shift away from bicycles and towards cars suggests fertile ground for a student led "bicycle to and on campus" campaign - a large portion of students live within two miles of campus across a very level and generally sunny suburban terrain crisscrossed with bike paths and bike lanes, a very bike-friendly environment.

In short, these activities work: as self-learning tools, as a way to increase student engagement with the class and with more sustainable practices, and as a way to decrease the ecological footprint of the student body and ultimately of the University itself.

\section{References:}

Chalkley, B., Blumhof, J., and Raggnardsdíttir, K. V. (2010). Geography, earth, and environmental sciences: A suitable home for ESD? In P. Jones, D. Selby, and S. Sterling (Eds.), Sustainability education: perspectives and practice across higher education (pp. 93-107). New York: Earthscan: 93107. 
Charmaz, K. 2014. Constructing grounded theory. New York: Sage.

Cotton, D, and Winter, J. (2010). It's not just bits of paper and light bulbs': A review of sustainability pedagogies and their potential for use in higher education. In P. Jones, D. Selby, and S. Sterling (Eds.), Sustainability education: perspectives and practice across higher education (pp. 39-54). New York: Earthscan.

Hass, A. L., Underwood, C. A., and Larson, E. R. (2015). Beyond the climate change lecture: An experiential approach to teaching sustainability through personal investment. Paper presented to the Annual Conference of the Association of American Geographers. Chicago Ill.

Isenhour, C. (2015). Sustainable consumption and its discontents. In $\mathrm{H}$. Kopnina and E. Shoreman-Ouimet (Eds.), Sustainability: key issues (133154). London: Routledge.

Leiserowitz, A., Maibach, E., Roser-Renouf, C., Feinberg, G., \& Howe, P. (2013). Americans' actions to limit global warming. Yale University and George Mason University. New Haven, CT: Yale Project on Climate Change Communication.

Leonard, A. (2010). The story of stuff: how our obsession with stuff is trashing the planet, our communities, and our health - and a vision for change. New York: Simon and Schuster.

Moseley, W.G., Perramond, E. Hapke, H. and Laris, P. (2013). An introduction to human-environment geography: local dynamics and global processes. Hoboken, NJ: Wiley/Blackwell.

Moser, S. C. (2007). More bad news: the risk of neglecting emotional responses to climate

change information. In S. C. Moser \& L. Dilling (Eds.), A climate for change: communicating climate change and facilitating social change (pp. 64-80). Cambridge, UK: Cambridge University Press.

Rachelson, A. (2014). Sustainability education: the community college perspective. Journal of sustainability education. http://www.jsedimensions.org/wordpress/content/sustainability-educationthe-community-college-perspective_2014_06/

Robbins, P., Hintz, J., and Moore, S. A. (2013). Environment and society: a critical introduction (2nd Edition). Somerset, NJ: John Wiley \& Sons

Saylany, C. and Blumstein, D. (2011). The failure of environmental education (and how we can fix it). Berkeley, CA: University of California Press.

Sterling, S. (2009). Ecological intelligence: Viewing the world relationally. In A. Stibbe (Ed.), The handbook of sustainability literacy: skill for a changing world (pp. 77-83). Devon, UK: Green Books.

Wals, A. and Blewitt, J. (2010). Third-wave sustainability in higher education: Some international trends and developments. In P. Jones, D. 
Selby, and S. Sterling (Eds), Sustainability education: perspectives and practice across higher education (55-73). New York: Earthscan.

Walsh, E. M., Jenkins, D. and Cordero, E. (2016). The promise of an energy tracker curriculum for promoting home-school connections and youth agency in climate action. Journal of sustainability education. Vol. 11, February 2016 ISSN: 2151-7452

http://www.jsedimensions.org/wordpress/content/the-promise-of-an-energytracker-curriculum-for-promoting-home-school-connections-and-youthagency-in-climate-action_ 